\title{
A Poverty-Focused Evaluation of Commodity Tax Options
}

\author{
B. Essama-Nssah ${ }^{\ddagger}$
}

The difficulties faced by many developing countries in raising revenue from direct taxes have forced them to rely heavily on indirect taxes to finance development interventions. The purpose of this paper is to illustrate how to identify socially desirable options for commodity taxation in the context of a poverty reduction strategy. Within the logic of social evaluation the author assesses tax options on the basis of value judgments underlying members of the additively separable class of poverty measures. The criterion hinges on both the pattern of consumption of each commodity and the price elasticity of the poverty measure used. An application of this methodology to data for Guinea shows that many components of food expenditure (particularly cereals, grains and roots) would be good candidates for exemption from VAT. Even though expenditure on health and education is distributed in favor of the non-poor, their importance for human capital development argues for a program of targeted subsidies in a broader context of cost recovery.

Keywords: Poverty reduction, Commodity taxation, Social evaluation, Guinea

JEL Classification: D12, D63, H22, H31, I32, I38

World Bank Policy Research Working Paper 4245, June 2007

The Policy Research Working Paper Series disseminates the findings of work in progress to encourage the exchange of ideas about development issues. An objective of the series is to get the findings out quickly, even if the presentations are less than fully polished. The papers carry the names of the authors and should be cited accordingly. The findings, interpretations, and conclusions expressed in this paper are entirely those of the authors. They do not necessarily represent the view of the World Bank, its Executive Directors, or the countries they represent. Policy Research Working Papers are available online at http://econ.worldbank.org.

'Forthcoming in the Journal of International Development. The author is grateful to David Coady, Jean-Yves Duclos, and Peter J. Lambert for useful comments on an earlier version of this paper.

‡ Poverty Reduction Group, MSN: MC4-415, World Bank,1818 H Street, NW, Washington, D.C.20433, USA; Email: bessamanssah@worldbank.org; Telephone: (202) 473-7564; Fax: (202) 522-3283 


\section{Introduction}

It is commonly believed that maintaining and improving the living standard of a population is the ultimate objective of public policy and a fundamental expectation of the governed (Sen et al. 1987). Every policymaker should therefore strive to make people capable of choosing to live well. This Aristotelian view of the world underscores the importance of public finance for development. Indeed, the pursuit of this basic policy goal entails raising revenue and reallocating it to potential beneficiaries through public spending. Furthermore, the way public spending is financed and allocated is bound to affect the behavior of socioeconomic agents and the distribution of economic welfare within society (World Bank 1988).

Developing countries confront a host of macroeconomic challenges in the design and implementation of development strategies and policies. These challenges often stem from a poor policy response to exogenous shocks or from careless fiscal and monetary policies. In the 1980s and much of the 1990s, developing countries experienced a severe economic crisis linked to the two oil price shocks of 1973 and 1979, and the sharp decline in the world price of non-oil commodities between 1980 and 1987 . These shocks left many countries saddled with unsustainable imbalances in terms of current account deficits, excessive debt and fiscal deficits. The crisis also brought fiscal adjustment to the forefront of the development agenda. Such an adjustment entails a modification in the way the public sector raises resources from the private sector through taxes or charges on current or future economic activities, and redistributes these resources in the form of public spending. 
Ultimately, public spending is constrained by the ability of the tax system to produce revenue beyond what may be available from other sources. When faced with mounting budget deficits after significant expenditure cuts, many developing countries have had to reform their tax systems to increase revenue. This invariably entails a restructuring of the tax base and a modification of rates. This side of fiscal adjustment is the focus of our paper with particular emphasis on the reform of commodity taxation. This emphasis stems from the fact that developing countries have serious difficulties raising revenue from direct taxes on individuals and firms due to the fact that many potentially taxable transactions take place in a sizable informal sector of the economy. These countries are thus forced to rely heavily on indirect taxes on goods and non-factor services (such as sales, excise, and value added taxes) ${ }^{1}$. It is estimated that developing countries derive about 40 percent of their tax revenue from indirect taxes and 25 percent from income tax (Keen and Simone 2004). Over time, there has also been a significant shift from trade to domestic taxes as a result of the process of trade liberalization. Finally, in the 1990s, many developing countries adopted the value-added tax or VAT as a preferred means to tax consumption.

The purpose of this paper is to illustrate how to identify socially desirable options for commodity taxation in the context of a poverty reduction strategy. The perspective of development as empowerment has prompted the international community to declare poverty eradication a basic objective of development and therefore a benchmark measure

\footnotetext{
${ }^{1}$ Indirect or commodity taxes generally include taxes on domestic production and consumption, and on international trade. Production taxes are placed on goods before they enter the distribution chain while consumption taxes are levied on the sale of final goods only (World Bank 1988). A pure consumption tax is levied at the retail stage for all domestically consumed goods whether imported or produced locally. The value added tax or VAT is applicable to all transactions within the production-distribution chain all the way to the retail point. However, all intermediate purchasers can claim taxes paid against taxes due on sales. This is what makes the VAT a commodity tax on consumption (the final purchaser has no way to recuperate the amount paid in taxes).
} 
of the performance of socioeconomic systems. In this context, poverty must be seen as the deprivation of basic capabilities to lead the kind of life that one has reason to value (Sen 1999). A well designed and implemented public finance policy can therefore be a powerful tool for promoting poverty-reducing economic growth.

We frame our approach within the logic of social impact analysis understood as an assessment of variations in individual and social welfare attributable to the implementation of a policy. We maintain that, the observed poverty in a given society depends fundamentally on individual behavior and endowments (internal e.g. will and ability, and external such as ownership of assets and access to social support), and the socio-political arrangements that govern social interaction. We can therefore restate the focal policy problem as one of restructuring a system of indirect taxes to maintain or increase yield, reduce distortions and minimize the burden on the poor. This is basically a problem of optimal commodity taxation, the solution of which falls within the normative approach to policymaking which seeks to maximize a social welfare function subject to the economy's resource, technology and institutional constraints (Dixit 1996, Diamond and Mirrlees 1971a, b).

To identify desirable changes from the status quo, we need to compute the consequences of the policy reform and use explicit value judgments to assess these consequences. This is the standard approach underlying the modern theory of tax reform (Newbery and Stern 1987). Within this general framework, the computation of individual gains or losses relies on two basic assumptions: (1) the principle of optimization is used to characterize individual behavior, and (2) competitive markets 
govern interactions ${ }^{2}$ among socioeconomic agents. The optimal behavior of a socioeconomic agent is represented by a maximum value function (e.g. indirect utility) indicating the maximum value of the (individual) objective function in terms of various parameters underpinning the optimization problem (e.g. prices and the fixed budget). One can then invoke the envelope theorem to calculate the impact of changes in these parameters on the objective function (Dixit 1990).

In the public finance tradition (Drèze and Stern 1987, Newbery and Stern 1987, Slemrod and Yitzhaki 2001, Yitzhaki 2003), social desirability of a policy is judged on the basis of the variation of a social welfare function with respect to changes in individual utility functions induced by changes in policy instruments. This function is usually assumed to be a member of the Bergson-Samuelson family where social welfare is defined in terms of individual (indirect) utility functions. Thus the social impact of a policy change depends on the specification of this function on the basis of a set of value judgments.

The poverty focus of this paper requires a social evaluation criterion that pays special attention to the outcomes of the poor. We therefore base the assessment on poverty measures satisfying Sen's focus axiom. These measures are invariant with respect to the welfare of the non-poor (Sen 1997). In other words, evaluation is conducted on basis of a truncated distribution of outcomes. Truncation occurs at the poverty line. Our approach is consistent with Besley and Kanbur's (1988) analysis of the poverty impact of a reallocation of food subsidies at the margin. This approach is also similar to that of Bibi and Duclos (2007) or Son and Kakwani (2006). In particular it

\footnotetext{
${ }^{2}$ Within this setting, each person's claims to available goods and services are limited by the amount of income obtainable by that person's successful sale of something of value on the market. Lindblom (2001) calls this type of interaction, the rule of quid pro quo.
} 
relies on the logic underlying a measure of the pro-poorness of economic growth proposed by Essama-Nssah and Lambert (2006).

The outline of the paper is as follows. Section 2 presents the evaluative framework. It explains the computation of changes in individual welfare attributable to the tax reform, and the ranking of social states on the basis of poverty outcomes. Section 3 applies the method to data for Guinea. Concluding remarks are presented in Section 4.

\section{Evaluation Framework}

According to Sen (1999), any evaluative approach is characterized by its informational basis. This entails a distinction between the information required in passing judgments within the chosen approach and that which has no direct evaluative role. Our approach is essentially welfarist to the extent that it focuses on both individual and social welfare. Policy evaluation therefore requires the identification of impact on individuals as well as the specification of an aggregation rule to translate individual outcomes into social impact.

\section{Individual Outcomes}

Assessing the impact of policies on individual welfare and poverty status requires an explicit linkage between policy instruments and the determinants of individual living standard. In particular, commodity taxes affect prices at which such commodities are sold. We therefore need an expression of individual (or household) welfare as a function of relevant prices. Under the simple assumption that the consumer has an exogenous budget $\mathbf{x}$ to spend on a set of $\mathbf{m}$ commodities at fixed prices, the indirect utility is the maximum level of utility attainable given the outlay and the prevailing prices. This 
function can be formally written as (Deaton and Muellbauer 1980): $v(x, p)=\max _{q}[u(q) ; p \cdot q=x]$, where $\mathbf{q}$ is an m-dimensional vector of quantities of commodities and $\mathbf{p}$ the corresponding vector of consumer prices. We assume that producer prices are not affected by the reform. They can therefore be normalized to unity so that we express the consumer price of commodity $\mathbf{k}$ as a function of the producer price and the applicable tax (or subsidy) ${ }^{3}$ rate $\mathbf{t}_{\mathbf{k}}$. That is: $p_{k}=1+t_{k} ; k=1,2, \ldots, m$.

We can invoke Roy's identity to compute the welfare impact of a marginal change in the price of commodity $\mathbf{k}$ induced by a marginal change in the applicable tax. According to this identity, the Marshallian demand function of a commodity is equal to the negative of the first-order derivative of the indirect utility function, divided by the marginal utility of income. Formally we write.

$$
q_{k}(x, p)=-\frac{\partial v / \partial t_{k}}{\partial v / \partial x}=-\frac{\partial v / \partial p_{k}}{\partial v / \partial x}
$$

This expression implies that $\mathbf{d} \boldsymbol{v}^{*}(\mathbf{x}, \mathbf{p})=-\mathbf{q}_{\mathbf{k}}(\mathbf{x}, \mathbf{p}) \mathbf{d} \mathbf{p}_{\mathbf{k}}$ measures the welfare loss (in monetary terms) induced by a marginal increase ${ }^{4}\left(\mathbf{d t}_{\mathbf{k}}\right)$ in the price of commodity $\mathbf{k}$. In this setting, note that $\mathbf{d p}_{\mathbf{k}}=\mathbf{d t}_{\mathbf{k}}$.

To assess the poverty implications of this price change, we need to define a measure of poverty at the individual or household level (depending of the unit of analysis). Let $\mathbf{z}$ be the poverty line and $\psi(\mathbf{x} \mid \mathbf{z})$ an indicator of poverty (or deprivation) for an individual with total level of expenditure (or real income) equal x. Following Kakwani (1999), we assume that: (i) the poverty indicator is equal to zero when $\mathbf{x}$ is

\footnotetext{
${ }^{3}$ In this context, a subsidy is considered a negative tax on the relevant commodity.

${ }^{4}$ A rise in a subsidy would be associated with a welfare gain. Also, $v^{*}(\mathrm{x}, \mathrm{p})$ is equal to the indirect utility normalized by the marginal utility of income.
} 
greater or equal to the poverty line; (ii) the indicator is a decreasing convex function of $\mathbf{x}$, given $\mathbf{z}$. Thus the first-order derivative with respect to $\mathbf{x}$ is negative, given $\mathbf{z}$. In other words, $\psi^{\prime}(x \mid z)=\frac{\partial \psi(x \mid z)}{\partial x}<0$.

The observed demand functions are a consequence of optimal behavior. Hence, the level of expenditure $\mathbf{x}$ represents the minimum required to attain utility $v^{*}(\mathbf{x}, \mathbf{p})$. Thus when the price of commodity $\mathbf{k}$ increases by a small amount, the consumer faces a loss of real income $\mathbf{d x}=-\mathbf{q}_{\mathbf{k}}(\mathbf{x}, \mathbf{p}) \mathbf{d} \mathbf{p}_{\mathbf{k}}$. We compute the corresponding marginal poverty increase as follows.

$$
\frac{\partial \psi(x \mid z)}{\partial p_{k}}=\frac{\partial \psi(x \mid z)}{\partial x} \cdot \frac{\partial x}{\partial p_{k}}=-\psi^{\prime}(x \mid z) q_{k}
$$

In the case of a subsidy, the marginal reduction in poverty is equal to the absolute value of expression (2.2).

\section{Aggregation and Ranking}

The ranking of potential tax options is based on the impact of the tax reform on the overall poverty. We focus here on members of the class of additively separable poverty measures defined by the following expression, where $\mathbf{f}(\mathbf{x})$ stands for the density function of real income $\mathbf{x}$ within the population.

$$
\theta=\int_{0}^{z} \psi(x \mid z) f(x) d x
$$

Members of this class are additively separable in the sense that the deprivation felt by an individual depends only on a fixed poverty line and the individual economic welfare not on the welfare experienced by others in society. They include such poverty indices as the Foster Greer Thorbecke (1984) family and the Watts measure. The Foster Greer and Thorbecke (FGT) family is characterized by the following deprivation function: 
$\psi_{\alpha}(x \mid z)=\{\max [(1-x / z), 0]\}^{\alpha}$. When $\alpha$ is equal to zero, one or two, equation (2.3) leads respectively to the headcount ratio $(\mathbf{H})$, the normalized poverty deficit (or poverty gap), and the squared poverty gap. The deprivation function underlying the Watts index is similarly defined: $\psi_{\alpha}(x \mid z)=\max \left[\ln \left(\frac{z}{x}\right), 0\right]$.

Equations (2.2) and (2.3) imply that the change in overall poverty associated with a marginal increase in the price of commodity $\mathbf{k}$ is equal to:

$$
\frac{\partial \theta}{\partial p_{k}}=-\int_{0}^{z} q_{k} \psi^{\prime}(x \mid z) f(x) d x
$$

It is more convenient to couch the analysis in terms of elasticity. Thus, we write the price elasticity of poverty for commodity $\mathbf{k}$ as:

$$
\varphi_{k}(\theta)=\frac{\partial \theta}{\partial p_{k}} \cdot \frac{p_{k}}{\theta}=-\frac{1}{\theta} \int_{0}^{z} p_{k} q_{k} \psi^{\prime}(x \mid z) f(x) d x
$$

Furthermore, the price elasticity of real income with respect to commodity $\mathbf{k}$ is equal to the negative of the budget share of commodity $\mathbf{k}$ (Deaton and Muellbauer 1980).

$$
\frac{\partial x}{\partial p_{k}} \cdot \frac{p_{k}}{x}=-\frac{p_{k} q_{k}}{x}=-w_{k}(x)
$$

This expression means that, when the price of commodity $\mathbf{k}$ increases by 1 percent, real income $\mathbf{x}$ declines by an amount equal to the corresponding budget share, $\mathbf{w}_{\mathbf{k}}(\mathbf{x})$. Equation (2.5) is therefore equivalent to the following.

$$
\varphi_{k}(\theta)=-\frac{1}{\theta} \int_{0}^{z} x w_{k}(x) \psi^{\prime}(x \mid z) f(x) d x
$$

This elasticity is positive for a price increase and negative for a price reduction. It is a weighted sum of individual budget shares (interpreted as price elasticities of real 
income $^{5}$ ). Whether or not a change in the price of commodity $\mathbf{k}$ is favorable to the poor (i.e. pro-poor) depends on the distribution of these budget shares over the entire population.

We need a decision rule for declaring a price change pro-poor. For our purpose, an increase (reduction) in the price of commodity $\mathbf{k}$ is considered pro-poor if it induces an absolute increase (reduction) in poverty smaller (greater) than it would in a benchmark case $^{6}$. As a benchmark we select a situation where a one percent change in the price of $\mathbf{k}$ would have the same relative impact on real income $\mathbf{x}$. We construct such a hypothetical by assuming that everybody assigns the same proportion of real income, $\mathbf{w}_{\mathbf{0 k}}$, to the purchase of commodity $\mathbf{k}^{7}$. This constant budget share can be computed as the average budget share for commodity $\mathbf{k}$. That is:

$$
w_{0 k}=\frac{\int_{0}^{m_{x}} p_{k} q_{k}(x) f(x) d x}{\int_{0}^{m_{x}} x f(x) d x}=\frac{\int_{0}^{m_{x}} x w_{k}(x) f(x) d x}{\int_{0}^{m_{x}} x f(x) d x}
$$

where $\mathbf{m}_{\mathbf{x}}$ represents the highest level of real income in the population. The corresponding price elasticity of poverty is:

$$
\varphi_{0 k}(\theta)=-\frac{w_{0 k}}{\theta} \int_{0}^{z} x \psi^{\prime}(x \mid z) f(x) d x
$$

Since budget shares do add up to unity, the price elasticity defined by equation (2.9) can be rewritten as: $\varphi_{0 k}(\theta)=-\frac{w_{0 k}}{\theta} \int_{0}^{z} x\left(\sum_{k=1}^{m} w_{k}(x)\right) \psi^{\prime}(x \mid z) f(x) d x=w_{0 k} \sum_{k=1}^{m} \varphi_{k}(\theta)=w_{0 k} \varphi(\theta)$,

\footnotetext{
${ }^{5}$ Interestingly, this price elasticity is analogous to the growth elasticity of poverty proposed by EssamaNssah and Lambert (2006) in the context of measuring the pro-poorness of economic growth.

${ }_{7}^{6}$ The choice of a benchmark is analogous to selecting a level of significance in statistical analysis.

${ }^{7}$ This idea is similar to the use of a Lorenz curve to assess inequality. Indeed, within the Lorenz framework, the amount of observed inequality is inferred from a comparison of the actual distribution of economic welfare (as represented by income or expenditure) with a hypothetical distribution where everybody would have equal share.
} 
where $\varphi(\theta)=\sum_{k=1}^{m} \varphi_{k}(\theta)$ is the percentage change in poverty induced by a marginal increase in all prices (Son and Kakwani 2006).

A 1 percent increase in the price of commodity $\mathbf{k}$ would increase poverty by $\theta \varphi_{\mathbf{k}}$ under the observed distribution of budget shares, and by $\theta \varphi_{0 \mathbf{k}}$ in the benchmark case. To declare the price increase pro-poor one can make either an additive comparison or a comparison in ratio form. Consider the ratio form first. This leads to the following indicator.

$$
\xi_{k}(\theta)=\frac{\int_{0}^{z} x w_{k}(x) \psi^{\prime}(x \mid z) f(x) d x}{w_{0 k} \int_{0}^{z} x \psi^{\prime}(x \mid z) f(x) d x}=\frac{\int_{0}^{z} x \omega_{k}(x) \psi^{\prime}(x \mid z) f(x) d x}{\int_{0}^{z} x \psi^{\prime}(x \mid z) f(x) d x}
$$

Where $\omega_{k}(x)=\frac{w_{k}(x)}{w_{0 k}}$ is the budget share of commodity $\mathbf{k}$ at income level $\mathbf{x}$ normalized by the aggregate budget share. The ratio measure of pro-poorness is thus a weighted average of normalized budget shares among the poor (i.e. along the distribution of real income up to the poverty line). An increase in the price of $\mathbf{k}$ would be considered propoor if this indicator is less than one. In other words, an increase in the price of commodity $\mathbf{k}$ would hurt the poor less than the non-poor. Commodities for which this indicator is greater than one are good candidates for subsidization.

It is instructive to consider the additive comparison based on the following measure.

$$
\pi_{k}(\theta)=\theta\left(\varphi_{k}-\varphi_{0 k}\right)=-\int_{0}^{z} x \psi^{\prime}(x \mid z)\left[w_{k}(x)-w_{0 k}\right] f(x) d x
$$

This additive measure of pro-poorness is a weighted sum of the deviation of budget shares for commodity $\mathbf{k}$ from their mean, up to the poverty line. When this measure is 
negative, an increase in the price of commodity $\mathbf{k}$ would be pro-poor (i.e. it would hurt the non-poor more than the poor). In other words, $\pi_{k}(\theta)<0$. A poverty-focused fiscal reform would not advocate a subsidy on such a commodity. Expression (2.11) also reveals that $w_{k}(x)>w_{0 k} \forall x<z$ is sufficient for an increase in the price of commodity $\mathbf{k}$ to hurt the poor more than the non-poor, regardless of the poverty measure used among those defined in (2.3).

We now consider expressions for the price elasticity and measures of propoorness for specific poverty measures that we will use in the empirical section. The headcount ratio is equal to the cumulative distribution function of $\mathbf{x}$ evaluated at the poverty line. That is $\mathbf{H}=\mathbf{F}(\mathbf{z})$. The price elasticity of the headcount can be computed in terms of the equivalent variation in the poverty line as follows.

$$
\varphi_{k}(H)=-\left(\frac{\partial H}{\partial z} \frac{\partial z}{\partial p_{k}}\right) \frac{p_{k}}{H}=\frac{f(z) p_{k} q_{k}(z)}{H}=\frac{z f(z) w_{k}(z)}{H}
$$

This expression implies that when all prices increase by one percent, the headcount ratio increases by $\varphi(H)=\frac{z f(z)}{H}$. The corresponding ratio measure of pro-poorness is equal to:

$$
\xi_{k}(H)=\frac{w_{k}(z)}{w_{0 k}}=\omega_{k}(z)
$$

While the additive measure of pro-poorness is equal to the following expression:

$$
\pi_{k}(H)=z f(z)\left[w_{k}(z)-w_{0 k}\right]
$$

When using the headcount ratio to assess the pro-poorness of a price change, expressions (2.13) and (2.14) make it clear that such a judgment is based only on the budget shares of individuals located at the poverty line. This indicator does not use available information 
efficiently to the extent that it does not take into account the pattern of consumption of commodity $\mathbf{k}$ among the poor.

For the Watts index of poverty, the price elasticity is equal to:

$$
\varphi_{k}\left(\theta_{W}\right)=\frac{1}{\theta_{W}} \int_{0}^{z} w_{k}(x) f(x) d x
$$

The corresponding additive measure of pro-poorness is:

$$
\pi_{k}\left(\theta_{W}\right)=\int_{0}^{z}\left[w_{k}(x)-w_{0 k}\right] f(x) d x
$$

Thus a reduction in the price of commodity $\mathbf{k}$ (e.g. a subsidy) would be pro-poor if the average budget share for the poor is greater than the overall average budget share. That is: $\frac{1}{H} \int_{0}^{z} w_{k}(x) f(x) d x>w_{0 k}$. Note that the multiplicative measure of pro-poorness for the Watts index is equal to:

$$
\xi_{k}\left(\theta_{W}\right)=\frac{1}{w_{0 k} H} \int_{0}^{z} w_{k}(x) f(x) d x=\frac{1}{H} \int_{0}^{z} \omega_{k}(x) f(x) d x
$$

Generally, when $\alpha \geq 1$, the price elasticity of poverty associated with members of the FGT family is equal to ${ }^{8}$ :

$$
\varphi_{k}\left(\theta_{\alpha}\right)=\frac{\alpha}{\theta_{\alpha}} \int_{0}^{z} \frac{x}{Z}\left(1-\frac{x}{Z}\right)^{\alpha-1} w_{k}(x) f(x) d x
$$

This expression leads to the following measures of pro-poorness:

$$
\begin{aligned}
& \text { Given that } \mathrm{x} / \mathrm{z}=[1-(1-\mathrm{x} / \mathrm{z})] \text {, this elasticity can also } \quad \text { be written as: } \\
& \varphi_{k}\left(\theta_{\alpha}\right)=\frac{\alpha}{\theta_{\alpha}}\left[\int_{0}^{z} w_{k}(x)\left(1-\frac{x}{\mathrm{z}}\right)^{\alpha-1} f(x) d x-\int_{0}^{z} w_{k}(x)\left(1-\frac{x}{\mathrm{z}}\right)^{\alpha} f(x) d x\right] \text {. This decomposition }
\end{aligned}
$$
implies that the overall impact associated with the same change in all prices can simply be written as follows: $\varphi\left(\theta_{\alpha}\right)=\sum_{k=1}^{m} \varphi_{k}\left(\theta_{\alpha}\right)=\frac{\alpha}{\theta_{\alpha}}\left[\theta_{\alpha-1}-\theta_{\alpha}\right]$ (Son and Kakwani 2006). 


$$
\xi_{k}\left(\theta_{\alpha}\right)=\frac{\int_{0}^{z} \frac{x}{Z}\left(1-\frac{x}{z}\right)^{\alpha-1} \omega_{k}(x) f(x) d x}{\int_{0}^{z} \frac{x}{Z}\left(1-\frac{x}{z}\right)^{\alpha-1} f(x) d x}
$$

and

$$
\pi_{k}\left(\theta_{\alpha}\right)=\alpha \int_{0}^{z} \frac{X}{Z}\left(1-\frac{x}{Z}\right)^{\alpha-1}\left[w_{k}(x)-w_{0 k}\right] f(x) d x
$$

\section{The Social Cost of Public Funds}

In general, the concept of social cost of public funds establishes a relationship between the funds collected through taxation and the change in social welfare induced by the collection process. In the context of our poverty-focused framework, the poverty cost per additional dollar raised by increasing the tax on commodity $\mathbf{k}$ is defined by the following expression.

$$
\lambda_{k}(\theta)=\frac{\partial \theta / \partial t_{k}}{\partial R / \partial t_{k}}
$$

where $\mathbf{R}$ stands for government revenue from commodity taxation. We refer to this indicator as the marginal poverty cost of public funds. Given two commodities $\mathbf{j}$ and $\mathbf{k}$ such that $\lambda_{j}(\theta)<\lambda_{k}(\theta)$, in the context of the design of a revenue-neutral tax reform, it would be socially desirable to increase the tax on $\mathbf{j}$ and reduce the tax on $\mathbf{k}$ by the same amount.

To make the expression of the marginal poverty cost of funds more explicit, we

define the aggregate demand function for commodity $\mathbf{k}$ as $Q_{k}(p)=\int_{0}^{m_{x}} q_{k}(p ; x) f(x) d x$. The following expression defines public revenue from commodity taxation. 


$$
R(t)=\sum_{k=1}^{m} t_{k} Q_{k}
$$

Thus, a small change in the tax rate of commodity $\mathbf{k}$ leads to the following change in government revenues.

$$
M R_{k}=\frac{\partial R}{\partial t_{k}}=\left(Q_{k}+\sum_{j \neq k}^{m} t_{j} \frac{\partial Q_{j}}{\partial t_{k}}\right)
$$

Equations (2.4) and (2.23) and the fact that $\mathbf{d t}_{\mathbf{k}}=\mathbf{d p}_{\mathbf{k}}$ imply that the marginal poverty cost of funds is equal to:

$$
\lambda_{k}(\theta)=\frac{-\int_{0}^{z} q_{k} \psi^{\prime}(x \mid z) f(x) d x}{\left(Q_{k}+\sum_{j \neq k}^{m} t_{j} \frac{\partial Q_{j}}{\partial t_{k}}\right)}
$$

Following Ahmad and Stern (1987), the above expression may be transformed as follows. First, multiply both the numerator and the denominator by the price of $\mathbf{k}$. Second, multiply the second term of the denominator by the neutral element $\mathbf{1}=\left(\mathbf{p}_{\mathbf{j}} \mathbf{Q}_{\mathbf{j}} / \mathbf{p}_{\mathbf{j}} \mathbf{Q}_{\mathbf{j}}\right)$. This two-step transformation allows the use of data on household expenditure, and leads to the following alternative expression for the marginal cost of funds.

$$
\lambda_{k}(\theta)=\frac{-\int_{0}^{z} p_{k} q_{k} \psi^{\prime}(x \mid z) f(x) d x}{\left(p_{k} Q_{k}+\sum_{j \neq k}^{m}\left(\frac{t_{j}}{p_{j}}\right) \varepsilon_{j k} p_{j} Q_{j}\right)}
$$

In other words, letting $\mu_{x}=\int_{0}^{m_{x}} x f(x) d x$, the above indicator can be rewritten as: 


$$
\lambda_{k}(\theta)=\frac{-\int_{0}^{z} x \psi^{\prime}(x \mid z) w_{k}(x) f(x) d x}{\mu_{x}\left(w_{0 k}+\sum_{j \neq k}^{m}\left(\frac{t_{j}}{p_{j}}\right) \varepsilon_{j k} w_{0 j}\right)}
$$

The parameter $\boldsymbol{\varepsilon}_{\mathbf{j} \mathbf{k}}$ stands for the cross-price elasticity between commodity $\mathbf{j}$ and commodity k. Bibi and Duclos (2007) show that the marginal poverty cost of taxing commodity $\mathbf{k}$ can also be written as:

$$
\lambda_{k}(\theta)=\frac{-\int_{0}^{z} x \psi^{\prime}(x \mid z) \omega_{k}(x) f(x) d x}{\left(1+\frac{t_{k}}{p_{k}} \varepsilon_{k k}+\sum_{j \neq k}^{m}\left(\frac{t_{j}}{p_{j}}\right) \varepsilon_{j k} w_{0 j}\right)}
$$

The expression $\gamma_{k}=\frac{\mu_{x} w_{0 k}}{\partial R / \partial t_{k}}$ can be interpreted as the marginal efficiency cost of taxation. It is an indicator of the extent of leakage from the tax base associated with adjustment in behavior by the tax payer in response to changes in the tax burden (Slemrod and Yitzhaki, 2001). This may be thought of as an incentive effect of the tax on commodity k. Expression (2.26) reveals that the marginal social cost of public funds is a product of two components, one measuring the efficiency cost and the other is linked to the distributional characteristic of commodity $\mathbf{k}^{9}$. The latter can be written as $d_{k}(\theta)=\frac{\partial \theta / \partial t_{k}}{\mu_{x} w_{0 k}}$

\footnotetext{
${ }^{9}$ Bibi and Duclos (2007) present similar expressions and discuss necessary and sufficient conditions for a marginal tax reform to be both revenue neutral and poverty-reducing for all poverty measures satisfying some set of value judgments. Also note that the distributional characteristic of a commodity depends on the covariance between the consumption of that commodity and social weights defined by the structure of the poverty measure underlying the evaluation.
} 


\section{An Empirical Illustration}

We now use household level data for Guinea to illustrate the use of the above indicators to identify commodities or groups of commodities the taxation of which would be more or less (at the margin) desirable from the standpoint of poverty reduction. The database is a nationally representative sample of 4,416 households from the 1994 Integrated Household Survey.

Table 3.1: A Poverty Profile for Guinea (1994)

\begin{tabular}{lcccc}
\hline & Headcount & Poverty Gap & Squared Poverty Gap & Watts \\
\hline Conakry & 6.70 & 1.30 & 0.38 & 1.56 \\
Other Urban & 24.32 & 6.58 & 2.59 & 8.60 \\
Rural & 52.52 & 17.77 & 7.86 & 24.08 \\
\hline Guinea & 40.27 & 13.19 & 5.75 & 17.80 \\
\hline
\end{tabular}

Source: Author's calculations (results in percentage)

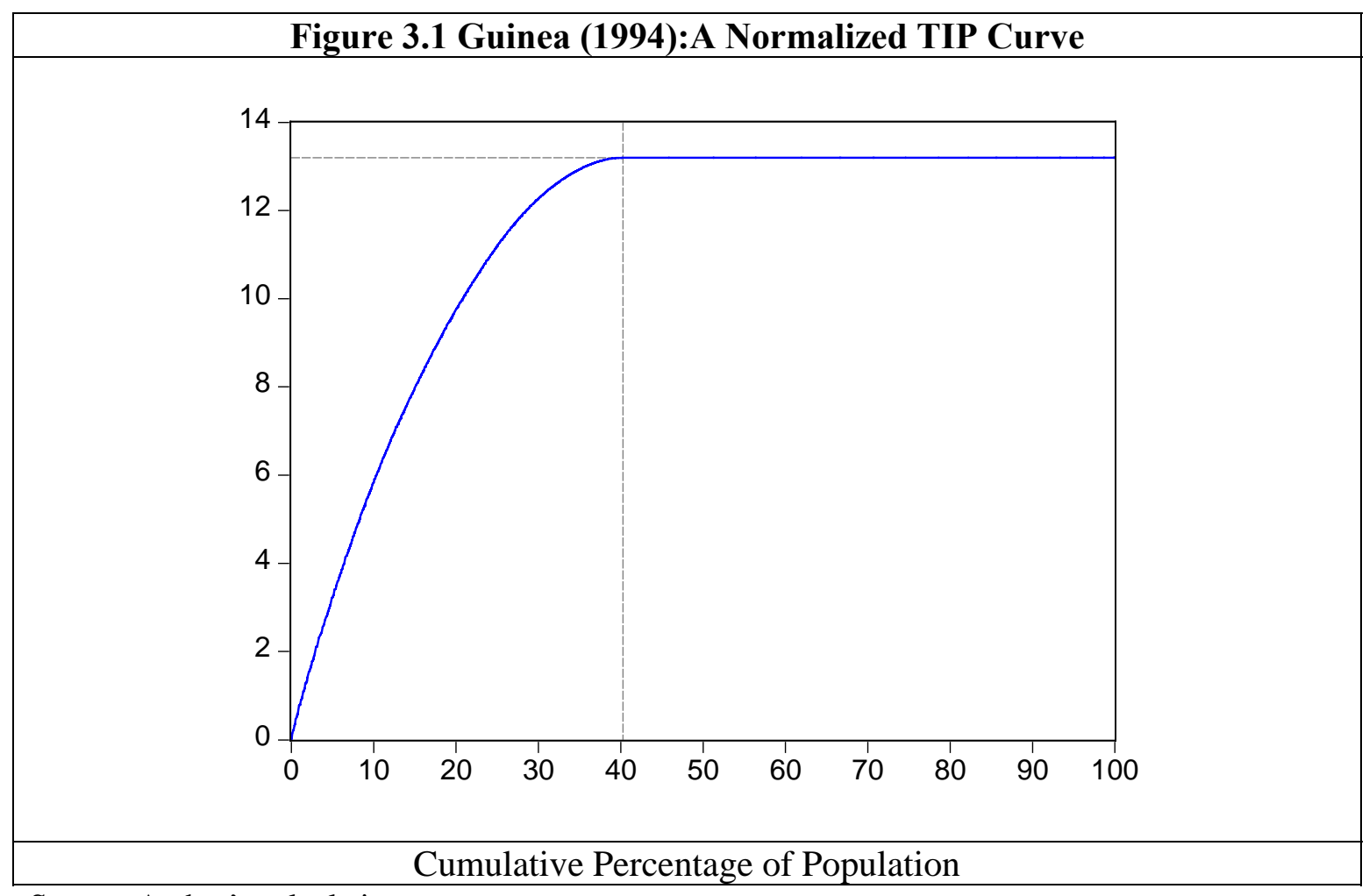

Source: Author's calculations 
Guinea is considered one of the poorest countries in Africa despite its rich endowment in agricultural, mineral and energy resources. The United Nations Report of Human Development has, for the past decade, ranked this country last or near the bottom among some 174 countries. In 1994, income poverty incidence was estimated at about 40 percent based on a poverty line set at about US\$300 per capita and per annum ${ }^{10}$. This is about 56 percent of the 1994 GDP per capita (US\$532). Table 3.1 shows a profile of income poverty in Guinea, as measured by members of the Foster-Greer-Thorbecke (FGT) family of poverty measures and the Watts index. All measures indicate that poverty is essentially a rural phenomenon. About 53 percent of the rural population lived in poverty in 1994. The urban centers outside the capital city of Conakry represent the next poorest areas with poverty incidence estimated at 24 percent. Poverty is lowest in the capital city, regardless of the measure used.

Figure 3.1 provides a global picture of poverty for the whole country based on the FGT measures. This is the so-called three I's of poverty (TIP) curve of Jenkins and Lambert (1997) ${ }^{11}$. The curve shows graphically three dimensions of aggregate poverty as follows: (a) the length of the non-horizontal segment reveals incidence, (b) the height of the curve at any point on the horizontal segment represents intensity, and (c) the degree of concavity translates inequality among the poor.

In January 2002, the Government of Guinea published a Poverty Reduction Strategy Paper (PRSP) describing an integrated and participatory approach to fighting poverty. The three pillars of this strategy are (Republic of Guinea 2002): (1) Boosting

\footnotetext{
${ }^{10}$ In local currency (Guinean Francs) this was equivalent to GNF293,714.

${ }^{11}$ The curve is obtained by ranking individuals from the poorest to the richest and partially cumulating individual contributions to the overall poverty. Individual contributions are based on the chosen deprivation function $\psi(\mathrm{x} \mid \mathrm{z})$. The three I's stand for (1) Incidence, (2) Intensity and (3) Inequality (among the poor).
} 
economic growth; (2) Promoting efficient and equitable provision of basic services; and (3) Improving governance and building human capital.

The strategy identifies two basic challenges in the area of fiscal management: revenue mobilization, and enhancing the efficiency of public expenditures. Between 1996 and 2000 central government revenues hovered around 10 percent of GDP while total expenditures ranged from 15 to 18 percent about (Republic of Guinea 2002).

To address this fiscal challenge in a socially desirable way, the strategy seeks to expand the tax base while protecting the vulnerable segments of the population. In particular, the government has decided to exempt from the value added tax $\left(\mathrm{VAT}^{12}\right)$ the following items considered basic necessities: rice, flour, edible oils, pharmaceuticals and school supplies. The social desirability of this policy decision may be evaluated on the basis of the methodology discussed in this paper.

Table 3.2 contains estimates of the distributional characteristic for 19 components of food expenditure, computed on the basis of the measure of pro-poorness defined by equation (2.10) for four poverty measures. Given the limitations we noted about measures associated with the headcount ratio, we focus our attention on those based on the poverty gap, the squared poverty gap and the Watts index. On the basis of these results, there are 11 food items or groups that might deserve special consideration in the context of marginal commodity tax reform. These include palm oil, smoked fish, rice (both local and imported), sugar, cereals, roots, grains, vegetables, oils and sweets. As the analytical framework revealed, the commodities for which the ratio measure of propoorness is greater than one are those with higher budget shares for low-income

\footnotetext{
${ }^{12}$ In Guinea, the VAT is assessed at a unique rate of 18 percent on the estimated value added to goods or services.
} 
households. Of the 11 food items identified, cereals, roots and grains have the highest value for the indicator.

Table 3.2. Guinea (1994): Distributional Characteristics of Components of Food Expenditure

\begin{tabular}{lcccc}
\hline & Headcount & Poverty Gap & Squared Poverty Gap & Watts \\
\hline Beef & 0.00 & 0.65 & 0.56 & 0.61 \\
Palm Oil & 0.00 & 1.22 & 1.16 & 1.19 \\
Bread & 1.34 & 0.78 & 0.72 & 0.75 \\
Fresh Fish & 0.00 & 0.53 & 0.45 & 0.49 \\
Smoked Fish & 0.00 & 1.10 & 1.14 & 1.12 \\
Local Rice & 7.91 & 1.33 & 1.30 & 1.30 \\
Imported Rice & 135.94 & 1.17 & 1.23 & 1.30 \\
Sugar & 0.28 & 1.10 & 1.07 & 1.09 \\
Cereals & 2.34 & 1.57 & 1.57 & 1.57 \\
Roots & 0.00 & 1.53 & 1.56 & 1.55 \\
Grains & 0.82 & 1.56 & 1.61 & 1.59 \\
Fruits & 0.00 & 0.99 & 0.91 & 0.95 \\
Vegetables & 1.59 & 1.26 & 1.28 & 1.28 \\
Meats & 2.10 & 0.83 & 0.76 & 0.79 \\
Livestock & 0.00 & 0.94 & 0.95 & 0.95 \\
Beverages & 0.00 & 0.57 & 0.47 & 0.52 \\
Oils & 1.96 & 1.14 & 1.08 & 1.10 \\
Sweets & 0.25 & 1.04 & 1.01 & 1.03 \\
Canned Food & 0.00 & 0.42 & 0.37 & 0.40 \\
\hline
\end{tabular}

Source : Author's calculations

We also computed distributional characteristics for two subsets of non-food commodities. The results are presented in tables 3.3 for health and education, and 3.4 for the rest of non-food expenditure components. Only 5 expenditure components out of 21 are associated with a value of the pro-poorness index greater than one for at least one poverty measure. These components are: consultation fees, other health expenditures, PTA (contributions to parent-teacher association), rent and ceremonies. The key point here is that most non-food expenditure components represent systematically a higher proportion of the budget of high-income households. Theoretically, a subsidy on these products would favor the non-poor. However, because expenditure on health and 
education is key to human capital accumulation and hence poverty reduction, it may be worth investigating the feasibility of targeted subsidies in a broader context of cost recovery.

Table 3.3. Guinea (1994): Distributional Characteristics of Components of Expenditure on Health and Education.

\begin{tabular}{lcccc}
\hline & Headcount & Poverty Gap & Squared Poverty Gap & Watts \\
\hline Consultation Fees & 0.00 & 1.00 & 1.22 & 1.07 \\
Medical Test & 0.00 & 0.34 & 0.23 & 0.30 \\
Hospitalization & 0.00 & 0.37 & 0.19 & 0.29 \\
Pharmaceuticals & 0.05 & 0.61 & 0.59 & 0.61 \\
Other Health & 0.38 & 1.07 & 1.04 & 1.06 \\
School Fees & 0.00 & 0.12 & 0.09 & 0.11 \\
PTA & 0.00 & 0.96 & 1.05 & 1.01 \\
School Supplies & 0.00 & 0.73 & 0.68 & 0.70 \\
Other Education & 0.00 & 0.50 & 0.53 & 0.52 \\
\hline
\end{tabular}

Source: Author's calculations

Table 3.4 Guinea (1994): Distributional Characteristics of Some Components of Non-Food Expenditure

\begin{tabular}{lcccc}
\hline & Headcount & Poverty Gap & Squared Poverty Gap & Watts \\
\hline Tobacco & 0.96 & 0.93 & 0.90 & 0.90 \\
Hygiene & 0.65 & 0.72 & 0.68 & 0.70 \\
Clothing & 0.43 & 0.95 & 0.90 & 0.92 \\
Personal Effects & 0.00 & 0.74 & 0.70 & 0.72 \\
Rent & 2.19 & 1.83 & 2.06 & 1.94 \\
Water & 0.00 & 0.15 & 0.12 & 0.13 \\
Electricity & 0.00 & 0.14 & 0.10 & 0.12 \\
Energy & 0.87 & 1.01 & 0.99 & 1.01 \\
Transportation & 0.00 & 0.26 & 0.26 & 0.26 \\
Recreation & 0.00 & 0.34 & 0.29 & 0.31 \\
Communication & 0.00 & 0.05 & 0.04 & 0.05 \\
Ceremonies & 0.34 & 1.01 & 1.10 & 1.05 \\
\hline
\end{tabular}

Source: Author's calculations.

Social desirability does not necessarily entail feasibility. There is a potential efficiency cost associated with taxation as socioeconomic agents are expected to adjust their optimal behavior in the face of a new configuration of incentives induced by a tax reform. There could also be significant administrative costs associated with a finer differentiation of commodities for the sake of protecting the poor. As noted earlier, the 
concept of marginal social cost of taxation allows one to account for efficiency cost. This requires information of price elasticity of demand. Table 3.5 presents estimates of the marginal social cost associated with 16 food commodities for which we have estimates of price elasticity (see tables A.1 and A.2 in the annex). The ranking of commodities depends on the value judgments underpinning the poverty measure used. By and large, the commodities with the highest social cost tend to be the same as the ones identified on the basis of distributional characteristics. FGT measures rank roots, grains, cereals, vegetables and local rice as commodities with highest marginal social cost. To this list, the Watts index would add palm oil, smoked fish, oils and livestock products.

Table 3.5: Guinea (1994): Marginal Social Cost for Some Components of Food Expenditure

\begin{tabular}{lcccc}
\hline & Headcount & Poverty Gap & Squared Poverty Gap & Watts \\
\hline Beef & 0.00 & 0.19 & 0.09 & 0.26 \\
Palm Oil & 0.00 & 0.35 & 0.18 & 0.50 \\
Bread & 0.85 & 0.23 & 0.12 & 0.33 \\
Fresh Fish & 0.00 & 0.16 & 0.08 & 0.23 \\
Smoked Fish & 0.00 & 0.31 & 0.18 & 0.47 \\
Local Rice & 5.21 & 0.41 & 0.22 & 0.60 \\
Cereals & 1.42 & 0.44 & 0.24 & 0.66 \\
Roots & 0.00 & 0.49 & 0.27 & 0.73 \\
Grains & 0.53 & 0.47 & 0.27 & 0.72 \\
Fruits & 0.00 & 0.31 & 0.15 & 0.44 \\
Vegetables & 1.08 & 0.40 & 0.22 & 0.60 \\
Meats & 1.40 & 0.26 & 0.13 & 0.37 \\
Livestock & 0.00 & 0.31 & 0.17 & 0.47 \\
Beverages & 0.00 & 0.21 & 0.09 & 0.28 \\
Oils & 1.32 & 0.36 & 0.19 & 0.51 \\
Sweets & 0.17 & 0.33 & 0.18 & 0.49 \\
\hline
\end{tabular}

Source : Author's calculations

\section{Conclusion}

The perspective of development as empowerment has prompted the international community to declare poverty eradication a basic objective of development, hence a benchmark measure of performance of development interventions. In the pursuit of this fundamental policy objective, many developing countries rely heavily on indirect taxes 
on goods and non-factor services to finance development interventions. This paper therefore seeks to demonstrate how to conduct a poverty-focused evaluation of public policy on the basis of the value judgments underlying members of the additively separable class of poverty measures.

In the particular case of commodity taxation, the evaluation criterion hinges on both the price elasticity of the poverty measure used and the consumption pattern for each commodity. To assess whether a price change for a given commodity induced by an indirect tax reform is favorable to the poor, the observed pattern of consumption of that commodity is compared to a benchmark case of equal budget shares across individuals (or households). Additive comparison leads to an indicator that is a weighted sum of the deviation of budget shares for commodity $\mathbf{k}$ from the aggregate share, up to the poverty line. The weights depend of the chosen poverty measure.

The methodology developed in the paper confirms the basic intuition that a progressive commodity tax has a higher rate on goods that constitute a higher proportion of the budgets of high-income individuals. An application of this methodology to survey data for Guinea shows that it is mostly components of food expenditure (particularly cereals, grains and roots) that deserve exemption from VAT. Our analysis also shows that health and education expenditures (like other non-food items) represent a higher proportion of the budget of high-income households. Given the importance of these services for the accumulation of human capital, it is desirable to implement a program of targeted subsidies in a broader context of cost recovery. The feasibility of these policy options deserves further investigation. 


\section{Annex: Price Elasticities Used in the Computation of Marginal Cost of Funds}

Table A.1. Guinea (1994): Cross Price Elasticities for Six Food Items.

\begin{tabular}{lcrrrrr}
\hline & Beef & Palm Oil & Bread & Fresh Fish & Smoked Fish & Local rice \\
\hline Beef & -0.324 & -0.019 & -0.021 & -0.014 & -0.009 & -0.096 \\
Palm Oil & -0.013 & -0.231 & -0.015 & -0.010 & -0.006 & -0.068 \\
Bread & -0.027 & -0.024 & -0.423 & -0.017 & -0.012 & -0.123 \\
Fresh Fish & -0.026 & -0.036 & -0.040 & -0.616 & -0.017 & -0.183 \\
Smoked Fish & -0.005 & -0.011 & -0.012 & -0.008 & -0.183 & -0.055 \\
Local Rice & -0.135 & -0.026 & -0.030 & -0.019 & -0.013 & -0.568 \\
\hline
\end{tabular}

Source : Setym International (1995)

Table A2. Guinea (1994) : Cross Price Elasticities for Groups of Food Items.

\begin{tabular}{lcccccccccc}
\hline & $\mathbf{1}$ & $\mathbf{2}$ & $\mathbf{3}$ & $\mathbf{4}$ & $\mathbf{5}$ & $\mathbf{6}$ & $\mathbf{7}$ & $\mathbf{8}$ & $\mathbf{9}$ & $\mathbf{1 0}$ \\
\hline 1.Cereals & -0.125 & -0.018 & -0.010 & -0.025 & -0.029 & -0.015 & 0.000 & -0.003 & -0.012 & -0.004 \\
2.Roots & -0.296 & -0.214 & -0.035 & -0.091 & -0.104 & -0.055 & -0.001 & -0.009 & -0.043 & -0.015 \\
3.Grains & -0.215 & -0.046 & -0.135 & -0.066 & -0.076 & -0.040 & -0.001 & -0.007 & -0.031 & -0.011 \\
4.Fruits & -0.249 & -0.053 & -0.030 & -0.203 & -0.088 & -0.046 & -0.001 & -0.008 & -0.036 & -0.013 \\
5.Vegetables & -0.290 & -0.062 & -0.035 & -0.089 & -0.250 & -0.054 & -0.001 & -0.009 & -0.042 & -0.015 \\
6.Meats & -0.267 & -0.057 & -0.032 & -0.082 & -0.094 & -0.185 & -0.001 & -0.009 & -0.038 & -0.014 \\
7.Livestock & -0.369 & -0.078 & -0.044 & -0.113 & -0.130 & -0.068 & -0.189 & -0.012 & -0.053 & -0.019 \\
Products & & & & & & & & & \\
8.Drinks & -0.530 & -0.113 & -0.064 & -0.162 & -0.186 & -0.098 & -0.002 & -0.288 & -0.076 & -0.027 \\
9.Oils & -0.279 & -0.059 & -0.033 & -0.085 & -0.098 & -0.052 & -0.001 & -0.009 & -0.183 & -0.014 \\
10.Sweets & -0.297 & -0.063 & -0.036 & -0.091 & -0.104 & -0.055 & -0.001 & -0.010 & -0.043 & -0.167 \\
\hline
\end{tabular}

Source : Setym International (1995) 


\section{References}

Ahmad, Ehtisham and Stern, Nicholas: 1987. Alternative Sources of Government Revenue: Examples from India, 1979-80. In David Newbery and Nicholas Stern (eds) "The Theory of Taxation for Developing Countries”. Washington, D.C.: The World Bank.

Besley Timothy and Kanbur Ravi. 1988. Food Subsidies and Poverty Alleviation. The Economic Journal, Vol. 98, No.392: 701-719.

Bibi Sami and Duclos Jean-Yves. 2007. Poverty-Decreasing Indirect Tax Reforms: Evidence from Tunisia. International Tax and Public Finance, Vol. 14, No.2:165-190.

Coady, David. 2006. Indirect Tax and Public Pricing Reform. In Aline Coudouel and Stefano Paternostro (eds), “Analyzing the Distributional Impact of Reforms". Washington D.C.: The World Bank. , and Skoufias Emmanuel. 2004. On the Targeting and Redistribution Efficiencies of Alternative Transfer Instruments. Review of Income and Wealth, Series 50, No. 1:11-27.

Creedy, John. 2001. Indirect Tax Reform and the Role of Exemptions. Fiscal Studies, Vol. 22, No. 4: 457-486.

Deaton, A., and J. Muellbauer. 1980. Economics and Consumer Behavior. Cambridge: Cambridge University Press.

Diamond, Peter A. and Mirrlees James A. 1971a. Optimal Taxation and Public Production I: Production Efficiency. The American Economic Review, Vol. 61, No. 1:8-27. 
Diamond, Peter A. and Mirrlees James A. 1971b. Optimal Taxation and Public Production II: Tax Rules. The American Economic Review, Vol. 61, No. 3:261-278.

Dixit, A. K. 1996. The Making of Economic Policy: A Transaction-Cost Politics Perspective. Cambridge (Massachussets): MIT Press.

. 1990. Optimization in Economic Theory. Oxford: Oxford University Press.

Drèze, Jean and Stern Nicholas. 1987. The Theory of Cost-Benefit Analysis. In A.J. Auerbach and M. Feldstein (eds), Handbook of Public Economics, Vol. II: 909-989.

Emran, M. Shahe and Stiglitz, Joseph E. 2005. On Selective Indirect Tax Reform in Developing Countries. Journal of Public Economics, 89: 599-632.

Essama-Nssah, B. and Lambert, Peter J. 2006. Measuring the Pro-poorness of Income Growth within an Elasticity Framework. Policy Research Working Paper No. 4035. Washington, D.C.: The World Bank.

Essama-Nssah, B. 2005. A Unified Framework for Pro-Poor Growth Analysis. Economics Letters 89: 216-221.

Foster J., Greer, J. and Thorbecke, E. 1984. A Class of Decomposable Poverty Measures. Econometrica, Vol. 52, No.3 , 761-766. (May).

Jenkins, S.P. and P.J. Lambert (1997). "Three 'I's of poverty" curves, with an analysis of U.K. poverty trends. Oxford Economic Papers, vol. 49, pp. 317-327.

Kakwani N. C. (1999). Inequality, welfare and poverty: three interrelated phenomena. In Silber, J. (ed.) “Handbook of Income Inequality Measurement”. Boston: Kluwer Academic Publishers. 
Keen , Michael and Simone, Alejandro. 2004. Tax Policy in Developing Countries: Some Lessons from the 1990s and Some Challenges Ahead. In Sanjeev Gupta, Benedict Clements and Gabriela Inchauste (eds.) “Helping Countries Develop: The Role of Fiscal Policy. Washington, D.C. International Monetary Fund (IMF).

Lindblom, C. E. 2001. The Market System: What Is It, How It Works and What to Make of It. New Haven, CT: Yale University Press.

Newbery, David and Stern, Nicholas. 1987. Introduction. In David Newbery and Nicholas Stern (eds) "The Theory of Taxation for Developing Countries". Washington, D.C.: The World Bank.

Republic of Guinea. 2002. Poverty Reduction Strategy Paper. Conakry: The Government of Guinea.

Sen, A. 1999. Development as Freedom. New York: Alfred A. Knopf . 1997. On Economic Inequality (Expanded edition with a substantial annex by James E. Foster and Amartya Sen). Oxford: Clarendon Press.

Sen, A. et al. 1987. The Standard of Living. New York: Cambridge University Press.

Setym International. 1995. Estimation des Coefficients d'Elasticité de la Consommation des Ménages par Rapport au Revenu et au Prix. Rapport de Mission Projet d'Appui du Développement SocioEconomique (PADSE), République de Guinée. Montréal : Setym International Inc.

Slemrod, Joel and Yitzhaki, Shlomo. 2001. Integrating Expenditure and Tax Decisions: The Marginal Cost of Funds and Marginal Benefits of Projects. National Tax Journal, Vol. 54, No.2 :189-201. 1996. The Costs of Taxation and the Marginal Efficiency Cost of Funds. IMF Staff Papers. Vol. 43, No.1: 172-198. 
Son, Hyun H. 2006. Assessing the "Pro-Poorness" of Government Fiscal Policy in Thailand. Public Finance Review, Vol. 34, No.4: 427-449. and Kakwani, Nanak. 2006. Measuring the Impact of Price Changes on Poverty. Working Paper No. 33, International Poverty Centre, Brazil.

Varian, Hal R. 1992. Microeconomic Analysis. New York: Norton \& Company.

World Bank. 2000. World Development Report 2000/2001: Attacking Poverty. Oxford: Oxford University Press.

, 1997. Guinea: A Socioeconomic Assessment of Well-Being and Poverty. Institutional and Social Policy Unit and Country Department 16, Report No.16465-GUI.

. 1991. Lessons of Tax Reform. Washington, D.C.: The World Bank. • 1988. World Development Report 1988: Public Finance and Development. Oxford: Oxford University Press.

Yitzhaki, Shlomo. 2003. Cost-Benefit Analysis and the Distributional Consequences of Government Projects. National Tax Journal, Vol. LVI, No. 2: 319-336.

, and Lewis, Jeffrey, D. 1996. Guidelines on Searching for Dalton-Improving Tax Reform: An Illustration with Data from Indonesia. The World Bank Economic Review, Vol. 10, No. 3, 541-62. 